\title{
THE MANAGEMENT OF POST-KERATOPLASTY ASTIGMATISM BY POST-OPERATIVE ADJUSTMENT OF A SINGLE CONTINUOUS SUTURE
}

\author{
M. W. HOPE-ROSS, P. J. McDONNELL, P. G. CORRIDAN, G. NAYLOR and A. TAN-YEE \\ Birmingham
}

\begin{abstract}
SUMMARY
Penetrating keratoplasty was performed in 39 consecutive patients. A 16 bite 10-0 nylon continuous suture was used. Post-operatively, the suture was adjusted to reduce astigmatism, as determined by refraction, keratoscopy and keratometry. Suture adjustment was performed if astigmatism was over 4 dioptres (D). The suture was tightened in the flatter meridian and loosened in the steeper meridian. Twenty-one patients had suture adjustment performed. Prior to adjustment, mean ( \pm standard deviation) astigmatism measured $6.33 \pm 1.38 \mathrm{D}$. Following adjustment, mean astigmatism was significantly reduced to $2.69 \pm 1.14 \mathrm{D}(p<0.0001)$. The average final astigmatism for the entire group was $2.66 \pm 1.12 \mathrm{D}$. The use of a continuous adjustable suture in penetrating keratoplasty significantly reduced the post-operative astigmatism in a group of patients undergoing penetrating keratoplasty.
\end{abstract}

Penetrating keratoplasty is a successful operation in the restoration of sight due to corneal opacification. Despite technological advances in microsurgery, post-operative astigmatism remains one of the major complications of penetrating keratoplasty. ${ }^{1}$ Astigmatism is caused by several factors: variable placement and tension of sutures, mismatch between donor and host wounds and irregular wound healing. Mismatch between donor and host wounds has been the subject of considerable research. Vacuum trephines have been designed to create a circular donor button and recipient bed. ${ }^{2}$ However, the use of vacuum trephines does not eliminate post-operative astigmatism. $^{3}$

A number of different suture techniques have been devised to manage astigmatism. Interrupted sutures, a combination of interrupted and continuous sutures, or

From: The Birmingham and Midland Eye Hospital, Birmingham, UK.

Correspondence to: Mr. P. J. McDonnell, The Birmingham and Midland Eye Hospital, Church Street, Birmingham B3 2NS, UK. continuous sutures have all been used. A newer technique is the use of a single continuous adjustable suture which is adjusted post-operatively. ${ }^{4}$ The suture is adjusted so that it is tightened in the flat meridian and loosened in the steep meridian. The purpose of this paper is to present our results, using the technique of a single adjustable suture, in a group of patients undergoing penetrating keratoplasty.

\section{PATIENTS AND METHODS}

A prospective trial was undertaken at the corneal clinic in the Birmingham and Midland Eye Hospital, from October 1990 to March 1992. All patients undergoing penetrating keratoplasty for avascular corneal disease were entered in the trial. Surgery was performed at the Birmingham and Midland Eye Hospital.

Thirty-nine patients were enrolled in the trial. There were 22 males and 17 females, ranging in age from 15 to 90 years (mean 46.8 years). The indications for penetrating keratoplasty are shown in Table I. None of the patients had undergone previous penetrating keratoplasty. Three patients had additional surgery at the time of corneal transplantation: an extracapsular cataract extraction and insertion of a posterior chamber lens was performed in 1 patient, removal of an anterior chamber lens was performed in 1 patient and a posterior chamber lens was inserted in 1 patient.

The surgical technique was standard throughout and performed by five different surgeons. General anaesthesia was used for all the patients. A fixation suture was inserted into the superior and inferior rectus muscles. The cornea was marked with a radial keratotomy marker, as an aid to suture placement. The sizes of the donor and host trephines were determined at the time of surgery using calipers to measure the corneal diameter and the site of the opacity or cone, in the case of keratoconus. In patients with keratoconus, the donor and host trephines were cut to the same size. In all other cases, the donor trephine was $0.25 \mathrm{~mm}$ larger than the host corneal trephine. 
Table I. Indications for penetrating keratoplasty in 39 avascular corneas

\begin{tabular}{lc}
\hline Diagnosis & Number \\
\hline Keratoconus & 17 \\
Pseudophakic bullous keratopathy & 10 \\
Fuchs' endothelial dystrophy & 4 \\
Traumatic corneal scar & 3 \\
Herpetic keratitis & 3 \\
Iridocorneal endothelial syndrome & 1 \\
Bacterial keratitis & 1 \\
Total & 39 \\
\hline
\end{tabular}

The donor material and host cornea were cut using a hand-held trephine. Four single 10-0 nylon sutures were placed at the 3, 6, 9 and 12 o'clock positions. A single 16 bite continuous 10-0 nylon suture was then used, commencing at the 1 o'clock position and proceeding in a clockwise direction. The continuous suture was tied at the 1 o'clock position. The four interrupted sutures were then removed. The anterior chamber was re-formed with balanced salt solution and the wound examined for leakage. The suture was then tightened so that the wound was watertight.

The fixation sutures were removed and a hand-held keratoscope was held over the cornea to determine any gross astigmatism. If the reflex was oval or D-shaped, the suture was adjusted at the time to give a more circular image. A subconjunctival injection of $0.5 \mathrm{ml}$ cefuroxime and $0.5 \mathrm{ml}$ betamethasone $0.1 \%$ was then given.

Patients were kept in hospital for an average of 4 days post-operatively. While in hospital, all were treated with 2-hourly topical dexamethasone $0.1 \%$, neomycin $0.35 \%$ and polymyxin $\mathrm{B}$ sulphate. If the inflammatory response was severe the dosage was increased to 1-hourly. Patients were discharged on the above topical medication used six times a day.

All patients were subsequently reviewed at 2 weeks, 6 weeks and 10 weeks post-operatively. If there were post-

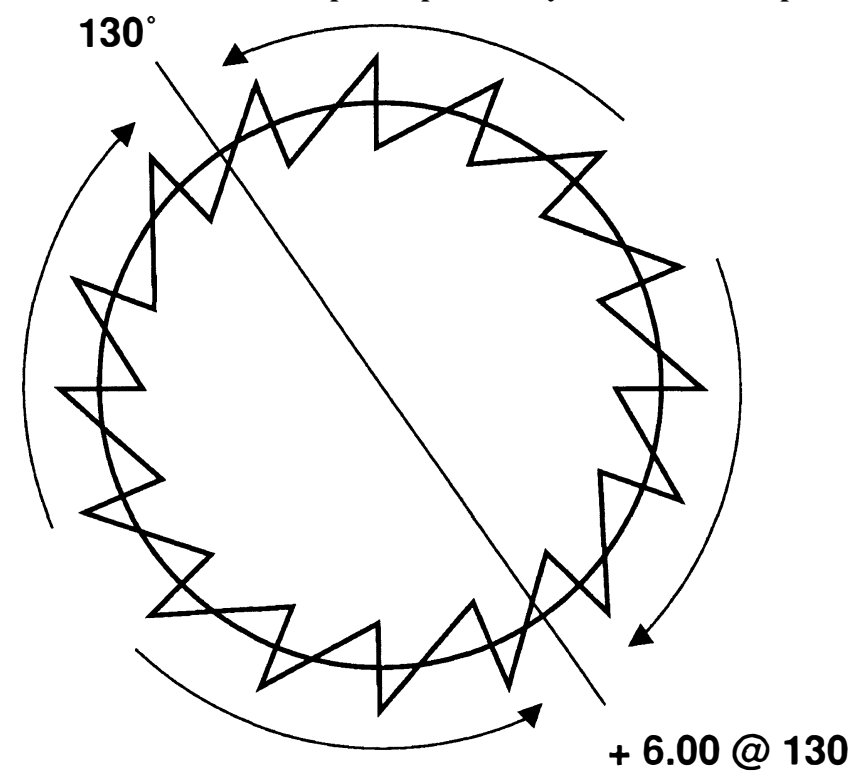

Fig. 1. Direction of suture adjustment. The suture is tightened in the flat axis and loosened in the steep axis. operative complications, they were seen more frequently. Patients were reviewed thereafter at 3-monthly intervals. On review, keratoscopy, retinoscopy and keratometry were performed. On the basis of these findings, suture adjustment was performed. If there was a discrepancy between these measurements, a decision regarding adjustment was made on the basis of the objective refraction.

Suture adjustment was performed if there was astigmatism greater than four 4 dioptres (D), the eye was quiet with no anterior segment inflammation and the graft was clear. Following adjustment, topical medication with dexamethasone $0.1 \%$, neomycin $0.35 \%$ and polymyxin B sulphate, four times daily, was given. The treatment regime was monitored at the next visit and altered depending on the clinical status.

In the first 3 cases, suture adjustment was performed in the operating theatre; as we became more familiar with the technique it was performed at the slit lamp. Three drops of oxybuprocaine $0.4 \%$ were given. The suture was then loosened from the overlying epithelium, grasped by suture-tying forceps and adjusted. The suture was adjusted to loosen it in the steep meridian and tighten it in the flat meridian (Fig. 1).

Immediately following suture adjustment, keratometry was performed to assess the effect of the adjustment. If astigmatism was still greater than $4 \mathrm{D}$, the suture was readjusted immediately. The patient was reviewed 4 weeks later and keratoscopy, retinoscopy and keratometry were performed. If the astigmatism was still above $4 \mathrm{D}$, suture adjustment was repeated. The follow-up period ranged from 18 to 79 weeks.

Statistical analysis was performed using the paired $t$-test.

\section{RESULTS}

Three patients suffered wound leaks in the immediate post-operative period. The suture was adjusted under topical anaesthesia, the leak stopped and did not recur.

Twenty-one patients in the group had astigmatism on refraction of greater than $4 \mathrm{D}$ and had the suture adjusted. The timing and number of adjustments for the group are shown in Table II. Suture adjustment was completed in all patients 32 weeks following surgery. One patient was lost to follow-up following adjustment and is not included in the results.

One complication occurred as a result of suture adjustment, when the suture broke; this was resutured under local anaesthesia. There were no infections, no wound leaks and no episodes of rejection following suture adjustment.

Table II. The timing of suture adjustment following penetrating keratoplasty

\begin{tabular}{lrccc}
\hline $\begin{array}{c}\text { Adjustment } \\
\text { no. }\end{array}$ & $\begin{array}{c}\text { No. of } \\
\text { eyes }\end{array}$ & $\begin{array}{c}\text { Range } \\
\text { (weeks) }\end{array}$ & $\begin{array}{c}\text { Mean } \\
\text { (weeks) }\end{array}$ & $\begin{array}{c}\text { Standard } \\
\text { deviation }\end{array}$ \\
\hline 1 & 20 & $5-29$ & 11.4 & 7.3 \\
2 & 9 & $9-32$ & 16.1 & 8.7 \\
3 & 1 & - & 13 & 0 \\
\hline
\end{tabular}


Table III. Final astigmatism, based on objective refraction in 38 patients following penetrating keratoplasty

\begin{tabular}{lccccccc}
\hline & \multicolumn{7}{c}{ Cylinder following refraction (dioptres) } \\
\cline { 2 - 8 } Groups & $\leqslant 1$ & $\leqslant 2$ & $\leqslant 3$ & $\leqslant 4$ & $\leqslant 5$ & $\leqslant 6$ & $\geqslant 6$ \\
\hline Adjusted & 2 & 5 & 9 & 2 & 1 & 1 & 0 \\
Not adjusted & 4 & 1 & 9 & 3 & 1 & 0 & 0 \\
Total & 6 & 6 & 18 & 5 & 2 & 1 & 0 \\
\hline
\end{tabular}

Final astigmatism $(n=38): 2.66 \mathrm{DC}$

There was a significant reduction in the post-operative astigmatism following adjustment. The final astigmatism was based on the results of the objective refraction. In the adjusted group, the average astigmatism prior to adjustment was $6.33 \pm 1.38 \mathrm{D}$ and following adjustment was reduced to $2.69 \pm 1.14 \mathrm{D}(p<0.0001)$. The final astigmatism for the entire group was $2.66 \pm 1.12 \mathrm{D}$ (Table III).

Two patients in the adjusted group had residual astigmatism greater than $4 \mathrm{D}$. Both patients had keratoconus. The first patient initially had $8 \mathrm{D}$ of astigmatism. Suture adjustment reduced this to $6 \mathrm{D}$. Suture adjustment was repeated 4 weeks later but failed to reduce the astigmatism. As the patient was wearing a contact lens in the fellow eye that was tolerated well, further suture adjustment was not performed and contact lenses were prescribed. The second patient initially had $8.5 \mathrm{D}$ of astigmatism. The first suture adjustment reduced the astigmatism to $5.75 \mathrm{D}$ and repeat adjustment further reduced it to $4.50 \mathrm{D}$. This was considered a satisfactory result and further adjustment was not performed. In the non-adjusted group 1 patient had residual astigmatism greater than $4 \mathrm{D}$. He had suffered a traumatic penetrating eye injury 4 weeks following penetrating keratoplasty. The graft was resutured with interrupted sutures and residual astigmatism was 4.75 D. Suture adjustment was not performed.

The final visual acuities are shown in Fig. 2. The causes of reduced visual acuity are shown in Table IV.

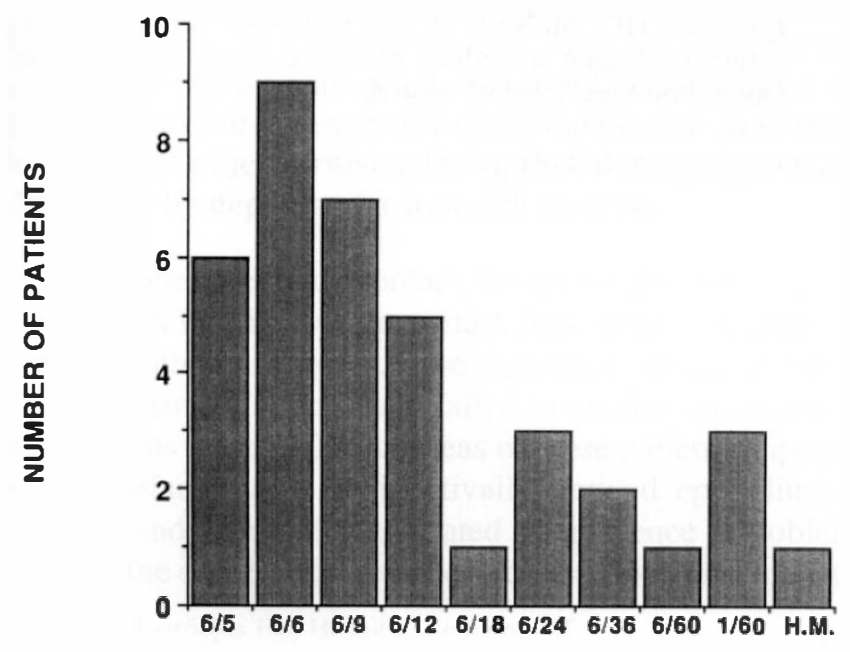

VISUAL ACUITY

Fig. 2. The final corrected visual acuity at the time of the last review.
Spectacles were prescribed if necessary. If the spectacle correction was not tolerated due to anisometropia or unilateral aphakia, contact lenses were fitted. Five patients had uncorrected visual acuity of $6 / 9$ or better and did not require a refractive correction. Seventeen patients were prescribed spectacles which were well tolerated. Three patients were happy with an uncorrected visual acuity of between 6/9 and 6/24 and were not prescribed corrective lenses. Eight patients required contact lenses. Of these, 3 patients were unilaterally aphakic, 4 patients had anisometropia due to large myopic errors, and 1 patient had astigmatism greater than $4 \mathrm{D}$. Five patients did not have a refractive correction prescribed due to visual acuity of $6 / 60$ or worse. No patient required refractive surgery post-operatively.

\section{DISCUSSION}

Astigmatism is a major problem following penetrating keratoplasty. The approaches to post-operative astigmatism are spectacles, contact lenses, suture manipulation and refractive surgery. Frequently patients undergoing penetrating keratoplasty have unstable ocular surfaces due to a variety of other coexistent ocular conditions and the use of contact lenses has a number of problems. ${ }^{5}$ Refractive surgery following penetrating keratoplasty has a role in cases of high residual astigmatism, but the results can be unpredictable and unstable. , $^{6,7}$

Suture manipulation is the mainstay of treatment for post-keratoplasty astigmatism. Interrupted sutures can be used and individual sutures removed selectively to reduce astigmatism. ${ }^{3,8}$ There are some problems with this technique. The axis of the cylinder can, following suture removal, shift around towards the next suture with no subsequent reduction in astigmatism. It requires many visits and suture removal attempts to correct severe degrees of astigmatism, and the process may take several months. Reduction of astigmatism does not always occur following manipulation of interrupted sutures and high residual astigmatic errors may persist.

Kirkness et al. ${ }^{9}$ studied a group of 198 patients (201 eyes) with keratoconus undergoing penetrating keratoplasty. Interrupted sutures, running sutures and a combination of interrupted and running sutures were used. Astigmatism was managed by selective suture removal and refractive surgery. Refractive surgery was performed in 36 eyes, and reduced astigmatism from a mean of $8.92 \mathrm{D}$ pre-operatively to $4.81 \mathrm{D}$ post-operatively. The average astigmatism for the entire group was $5.56 \mathrm{D}$.

Table IV. Causes of visual acuity $<6 / 12$ following penetrating keratoplasty

\begin{tabular}{lc}
\hline Diagnosis & No. of patients \\
\hline Cystoid macular oedema & 4 \\
Glaucoma & 2 \\
Age-related macular degeneration & 2 \\
Graft rejection & 1 \\
Retinal vein occlusion & 1 \\
Trauma & 1 \\
Total & 11 \\
\hline
\end{tabular}


The technique of a continuous adjustable suture in the management of post-operative astigmatism was first reported by M. Roper-Hall in $1982 .{ }^{10} \mathrm{He}$ described adjustment of a continuous suture to reduce astigmatism following cataract extraction and penetrating keratoplasty. McNeill and Wessels ${ }^{4}$ devised a technique to reduce postkeratoplasty astigmatism. A single continuous nylon suture was adjusted, to redistribute the suture tension and reduce astigmatism. The adjustment was performed on the basis of the keratometric findings. The average post-operative astigmatism following adjustment was $2.87 \mathrm{D}$. These findings have been confirmed by a number of other investigators. ${ }^{11,12}$ In our series, suture adjustment reduced astigmatism from $6.33 \mathrm{D}$ to $2.69 \mathrm{D}$. The final astigmatism in the entire group was $2.66 \mathrm{D}$.

Astigmatism can be monitored by keratoscopy, retinoscopy, keratometry and corneal topography. Suture adjustment is based on a combination of the results. The suture is adjusted so that it is loosened in the steep axis and tightened in the flat axis. The measurements are repeated and suture adjustment is repeated if astigmatism persists.

The precise tension of the suture is an important consideration in the ease of post-operative adjustment. If the suture is very tight, adjustment is difficult. We aimed to tie the suture so that the wound was watertight but no tighter. If the wound does leak post-operatively, it is relatively simple to adjust the suture at the slit lamp and stop the leak. Breakage of the suture can occur, and in our series we encountered this once. The suture was repaired and there were no long-term sequelae. Facilities must be available for suture repair should this be necessary. Graft rejection and infection are potential complications following suture manipulation. We did not encounter these complications in our series. We recommend the routine use of topical steroids and antibiotics following suture adjustment.

The advantages of the adjustable graft are manifold. It is possible to reduce astigmatism significantly. A low astigmatic correction allows the patient to wear spectacles, reduces the need for contact lenses and obviates the need for refractive surgery. We have found the technique of a single adjustable suture to be of enormous benefit in the management of post-keratoplasty astigmatism. It is simple to perform and allows fine adjustment of postkeratoplasty astigmatism.

Key words: Adjustable suture, Penetrating keratoplasty, Post-keratoplasty astigmatism.

\section{REFERENCES}

1. Perlman EM. An analysis and interpretation of refractive errors after penetrating keratoplasty. Ophthalmology 1981;88:39-45.

2. Waring GO, Hanna KD. The Hanna suction punch block and trephine system for penetrating keratoplasty. Arch Ophthalmol 1989;107:1536-9.

3. Harris DJ, Waring GO, Burk LL. Keratography as a guide to selective suture removal for the reduction of astigmatism after penetrating keratoplasty. Ophthalmology 1989; 96:1597-607.

4. McNeill JI, Wessels IF. Adjustment of single continuous suture to control astigmatism after penetrating keratoplasty. Refractive Corneal Surg 1989;5:216-23.

5. Casey TA. Corneal grafting. 2nd ed. Philadelphia: WB Saunders, 1984.

6. Troutman RC, Swinger C. Relaxing incision for control of postoperative astigmatism following penetrating keratoplasty. Ophthalmic Surg 1980;11:117-20.

7. Mandel MR, Shapiro MB, Krachemer JH. Relaxing incisions with augmentation sutures for the correction of post-keratoplasty astigmatism. Am J Ophthalmol 1987; 103:441-7.

8. Burk LL, Waring GO, Radjee B, Stulting RD. The effect of selective suture removal on astigmatism following penetrating keratoplasty. Ophthalmic Surg 1988;19:849-54.

9. Kirkness CM, Ficker LA, Steele AD, Rice NSC. The success of penetrating keratoplasty for keratoconus. Eye 1990;4:673-88.

10. Roper-Hall MJ. Control of astigmatism after surgery and trauma. Br J Ophthalmol 1982;66:556-9.

11. Temnycky GO, Lindal KJ, Aquavella JV, Erdey RA. Early visual rehabilitation following keratoplasty using a single continuous adjustable suture technique. Ophthalmic Surg 1990;22:208-12.

12. Lin DTC, Wilson SE, Reidy JJ, Klyce SD, McDonald MB, Kaufman HE, McNeill JI. An adjustable single running suture technique to reduce postkeratoplasty astigmatism. Ophthalmology 1990;97:934-8. 